\title{
Spontaneous thrombosis of a malformation of the vein of Galen
}

\author{
Guilherme P. Abrão', Leandro A. Barbosa², \\ Antenor T. Sá-Junior', José Guilherme M.P. Caldas ${ }^{3}$
}

Arteriovenous malformation of the vein of Galen (AMVG) is a rare congenital intracranial vascular malformation, which results in fistulous connections between primitive choroidal arteries and the median vein of the prosencephalon (MVP) of Markowisk ${ }^{1,2}$. The clinical picture varies according to age. In newborns and children under 12 months, the symptoms vary from congestive cardiac insufficiency to macrocephaly with skull bruit. In children over 3, adolescents and young adults, the most common symptoms are encephalalgia, effort-related syncopes, subarachnoid hemorrhage and retarded development. Diagnosis in adults is rare ${ }^{3}$. Spontaneous thrombosis of these lesions is an uncommon phenomenon and hardly ever found in the literature.

This paper reports the case of a female adolescent with spontaneous thrombosis of AMVG and discusses the radiological findings.

\section{CASE}

The patient is a 14-year-old female with a historical hydrocephaly since the age of 12 months and mildly retarded psychomotor development. She was directed to our service and no study of cerebral image had been carried out previously was found in the opportunity. Magnetic resonance imaging (MRI) of the brain was carried out (Fig 1), which revealed a heterogeneous lesion with well-defined edges and regular contours in the topography of the vein of Galen (VG) associated with mod-

\section{Correspondence} Guilherme P. Abrão Av. Fiji 74 04583-060 São Paulo SP - Brasil E-mail: guiabrao@yahoo.com.br

Received 22 June 2009

Received in final form 8 September 2009 Accepted 18 September 2009

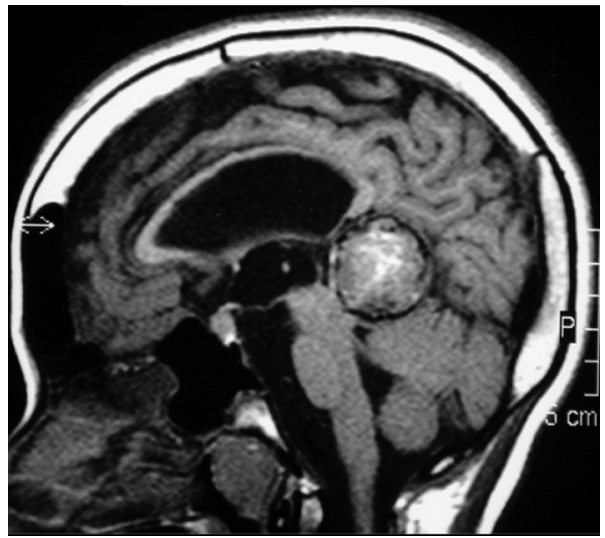

Fig 1. Sagittal view T1-weighted shows a heterogeneous lesion with well-defined edges and regular contours in the topography of the vein of Galen associated with moderate broadening of the lateral ventricles.

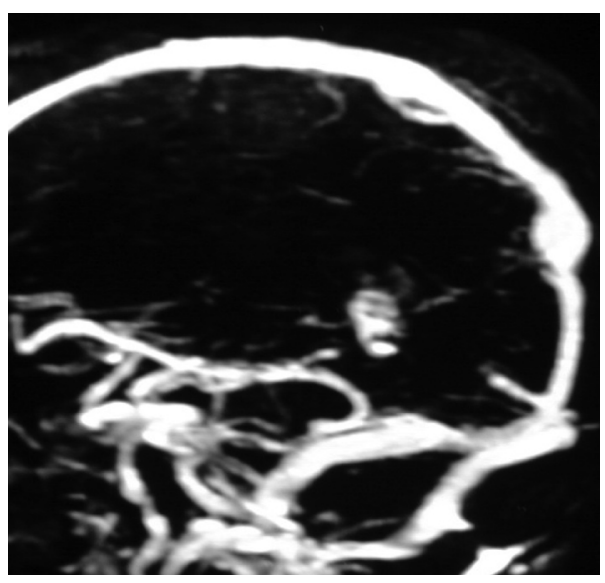

Fig 2. MR venography showing the absence of opacification of the deep venous system. Sagittal view.

deep venous system. Brain arteriography revealed no arteriovenous malformation and confirmed the opacification absence of the deep venous system with stenosis on exit routes of the transversal sinuses (terminal segments) (Fig 3). An X-ray taken

\section{TROMBOSE ESPONTÂNEA DE UMA MALFORMAÇÃO ARTERIOVENOSA DA VEIA DE GALENO}

Department of Interventional Neuroradiology, University of São Paulo School of Medicine, São Paulo SP, Brazil: 'MD, PhD; ${ }^{2} \mathrm{MD} ;{ }^{3} \mathrm{MD}, \mathrm{PhD}$, Director and Chairman. 


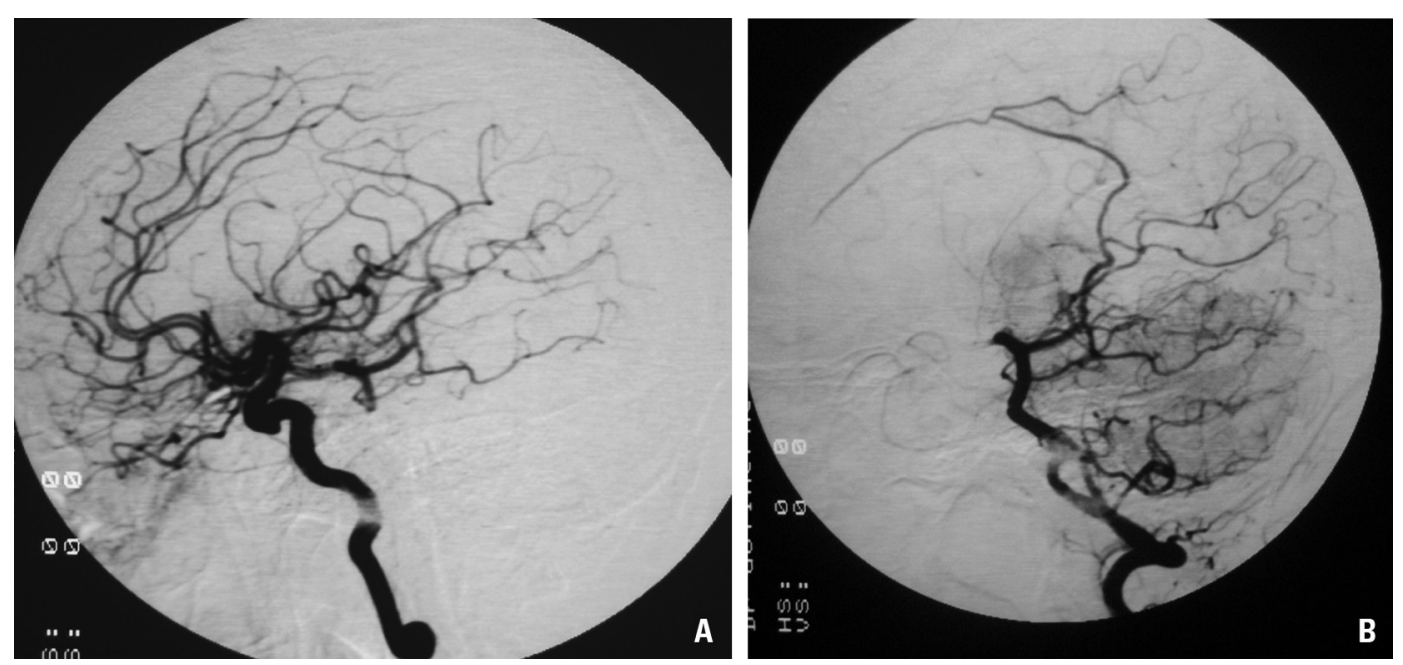

Fig 3. Right carotid $[A]$ and vertebral $[B]$ angiograms showing the absence of arteriovenous malformation. Lateral view.

during the examination evidenced gross calcification in the topography of the VG. The cerebral venous drainage pattern confirmed the diagnosis of AMVG with spontaneous thrombosis. No endovascular treatment was necessary due to the pre-existing thrombosis.

She has consented with this publication.

\section{DISCUSSION}

AMVGs develop between the $6^{\text {th }}$ and $11^{\text {th }}$ week of gestation, after the formation of Willis polygon ${ }^{1}$, which results in fistulous connections between primitive choroidal arteries and the median vein of the prosencephalon. The anomalous flow of these connections retards the involution of this embryonic vein and hinders the development of the VG. The shunt is maintained through the vein of Markowisk, draining into the sagittal sinus, usually by means of a persistent falcial sinus, with absence of straight sinus.

Two subtypes of AMVG are described based on their angioarchitecture. The choroidal form (more common) is characterized by abundant bilateral supply from the choroidal or thalamic arteries and this vascular supply occurs at the anterior face of the MVP. The mural type is supplied unilaterally or bilaterally by posterior collicular and choroidal arteries which drain directly through the wall of the persistent MVP. In such cases, obstruction of the exit route is common ${ }^{4}$.

Other venous anomalies associated with AMVG include anomalous and/or stenotic dural sinuses ${ }^{1,2}$. Some authors believe that the presence of these stenoses is responsible for the dilation of the $\mathrm{VG}^{4,5}$. Stenosis can occur as a result of the response of the venous endothelium to rapid and turbulent flow of the shunt ${ }^{6}$. Our observations showed that the patient presented stenosis of dural sinuses, and VG dilation could not be demonstrated to be due to previous thrombosis of the malformation.
Spontaneous thrombosis of the AMVG is a rare occurrence. The mechanisms involved are not yet well defined ${ }^{7}$. Kavanolov ${ }^{8}$ believes thrombosis occurs due to low blood flow and insufficient venous drainage. Based on his studies with animals, Brunelle ${ }^{6}$ found that increased pressure and venous flow turbulence lead to progressive myointimal proliferation with hypertrophy of the VG wall, resulting in gradual venous thrombosis. In the process of cerebral post-angiography thrombosis, the effects of contrast dyes have been discussed in the literature ${ }^{7,9}$. Hydrocephaly presence can accelerate thrombosis of the $\mathrm{AMVG}^{2,10,11}$. In our case, the patient presented a history of hydrocephaly beginning at the age of 1 , but without a diagnosis of AMVG.

The diagnosis of spontaneous AMVG occlusion and thrombosis of VG aneurysm is hard to find ${ }^{8,9}$. However, CT scanning can help by indicating the location, shape and presence of calcified capsules of lesions. MRI contributes in identifying the central hypersignal (extracellular methaemoglobin) and peripheral hyposignal (hemosiderin) which are characterized in T1-weighted images. Through TOF sequences and phase contrast, angioMR indicates the presence of thrombosis inside the venous ecstasia (VG aneurysm) that accompanies AMVG. The CT and MRI image associated with the clinical data may suggest a differential diagnosis of pineal tumors. The angiography demonstrated the absence of the deep venous system ${ }^{8}$ and confirmed the absence of VG opacification. Brain angiography shows the absence of flow in the AMVG, and the deep venous system ${ }^{8}$, which has confirmed the diagnosis of AMVG thrombosis.

In our case, we believe the vascular malformation should not have high flow otherwise the clinical features would be more obvious and the precautious can be safely detected. The thrombosis must have been progressive so otherwise the patient would present clinical obvious 
change. Despite spontaneous trombosis, the analysis of this case and its clinical evolution, resulted in retarded psychomotor development, demonstrate the aggressiveness of this disease and the need for early diagnosis prior to deterioration of the central nervous system, so that timely treatment can be provided.

Currently, treatment is the method of choice in cases of AMVG patent, with a mortality rate of $4 \%$ to $40 \%{ }^{8}$. Untreated cases usually evolve poorly and our review of the literature found only one report of a case in which spontaneous thrombosis occurred with a favorable evolution ${ }^{12}$. According to our observations, no treatment was imposed due to pre-existing thrombosis of the malformation.

In summary, spontaneous thrombosis of arteriovenous malformations of the vein of Galen is a rare condition that normally does not hinder an unfavourable clinical evolution. The diagnosis can be made by MRI and confirmed by cerebral angiography.

\section{REFERENCES}

1. Raybaud CA, Stroher CM, Hald JK. Aneurysms of the vein of Galen: embryonic considerations and anatomical features relating to the pathogenesis of the malformation. Neuroradiology 1989;31:109-128.
2. Lasjaunias P, TerBrugge K, Chiu M, Flodmark O, Chuang S, Goasguen J. The role of dural anomalies in vein of Galen aneuryms: report of six cases and review of the literature. AJNR Am J Neuroradiol 1987;8:185-192.

3. Lasjaunias P, TerBrugge K, Piske R, Lopez Ibor L, Manelfe C. Dilatation de la veine de Galien: formes anatomo-cliniques et traitement endovasculaire à propos de 14 cas explores et/ou traités entre 1983-1986. Neurochirurgie 1987;33:315-333.

4. Lasjaunias R. Vascular diseases in neonates, infants and children. Berlin: Springer-Verlag, 1997.

5. Garcia-Monaco R, Lasjaunias P, Berenstein A. Therapeutic management of vein of Galen aneurysmal malformations. In: Vinuela F, Halbach W, Dion JE, (Eds). Interventional neuroradiology: endovascular therapy of the central nervous system. New York: Raven Press, 1992:113-127.

6. Brunelle F. Arteriovenous malformation of the vein of Galen in children. Pediatr Radiol 1997;27:501-513.

7. Konus OL, llgit ET, Ozdemir A, Onal B. Spontaneous thrombosis of a vein of Galen aneurysmal malformation: possible effects of contrast media. Eur Radiol 2000;10:1456-1458.

8. Konovalov AN, Pitskhelauri DI, Arutiounov NV. Surgical treatment of the thrombosed vein of Galen aneurysm. Acta Neurochir 2002;144:909-915.

9. Beltramello A, Perini S, Mazza C. Spontaneously healed vein of Galen aneurysms. Child Nerv Syst 1991;7:129-134.

10. Horowitz MB, Jungreis CA, Quisling RG, Pollack I. Vein of Galen aneurysms: a review and current perspective. Am J Neuroradiol 1991;15:1486-1496.

11. Quisling RG, Mickle JP. Venous pressure measurement in vein of Galen aneurysms. Am J Neuroradiol 1989;10:411-417.

12. Kuzeyli K, Cakir E, Karaarslan G, et al. Spontaneous thrombosis of vein of Galen aneurysmal malformation after ventriculoperitoneal shunting. J Clin Neurosci 2004;11:439-442. 